\title{
Scanning Electron Microscopy Investigation of Enamel Surface Treated with Different Bleaching Agents
}

\section{Kemaloglu H, Atalayin $\mathrm{C}^{*}$ and Tezel $\mathrm{H}$}

Department of Restorative Dentistry, School of Dentistry, Ege University, Bornova, Izmir, Turkey

\begin{abstract}
Introduction: Bleaching of the discolored teeth has gained popularity in the public, but there is little information about the effects of bleaching products on tooth surface. The aim of this in vitro study was to evaluate the effects of different bleaching agents with different concentrations and activation methods on enamel surface.
\end{abstract}

Materials and methods: Human impacted third molars $(n=5)$ were divided into six parts and the specimens obtained from each tooth were randomly assigned to one of the six groups.

Group 1: No agent was used (positive control)

Group 2: 10\% Carbamide Peroxide (CP)

Group 3: $25 \%$ Hydrogen Peroxide (HP) + mercury metal halide light activation

Group 4: 38\% HP + quartz-tungsten-halogen light activation

Group 5: 38\% HP + diode laser activation

Group 6: $37 \%$ Orthophosphoric acid (negative control)

The specimens were kept in artificial saliva during the test period and then prepared for scanning electron microscopy analysis. Photomicrographs of representative areas were taken at 5000x and 10000x magnifications.

Results: There were no remarkable morphologic alterations in Group 1. Bleached groups showed alterations on surface smoothness. A slight increase in the enamel porosity occurred in Group 2. The appearance was similar to the unbleached enamel in Group 3. Mild intraprismatic structure dissolution formed with the increased porosity and concavity in Group 4. Minor alterations on surface smoothness and mildly increased porosity occurred in Group 5. Rough and uneven surface, which indicated alterations of the prismatic structure of enamel due to selective dissolution of the apatite crystals, consisted in Group 6.

Conclusion: The activation methods that shorten the contact time of the high concentrated peroxides can be useful to avoid the alterations caused by bleaching agents.

Keywords: Laser activation; Light activation; Scanning electron microscopy; Tooth bleaching

\section{Introduction}

Tooth bleaching has gained interest among people as aesthetic concerns and demand for perfect appearance increase over time. Teeth can discolorate during lifetime due to variety of intrinsic and extrinsic sources [1]. Treating the discolored teeth is not only an important factor for cosmetic intention but also for healthy mouth and physicosocial necessity [2]. Bleaching gels are commercialized with different trade names on dental market. Even though their content is nearly the same, manufacturers offer different advantages to customers. They try to influence dentists and patients with innovative activation methods that would provide enhanced bleaching effect in a shorter time with higher tooth whitening longevity.

Bleaching market includes three categories such as home bleaching, in-office bleaching and over-the-counter (OTC) products. "Home bleaching" of vital teeth can be achieved by the use of a custom made; vacuum-formed appliance with lower concentrated bleaching gels $(10 \%$ hydrogen peroxide (HP) or $10-20 \%$ carbamide peroxide (CP). Other method, termed "in-office bleaching" is applying higher concentrations of bleaching gels (30-38\% HP or 35-37\% CP) directly on to the tooth surface in the dental chair $[3,4]$. Patients cannot complete the home bleaching process for various reasons such as time requirement, discomfort and possible gingival irritation. In such cases, in-office bleaching techniques offer quicker whitening results with the help of various activation methods such as light, laser and etc. which accelerate the bleaching reaction.
Activated bleaching offers an improvement in terms of effectiveness, short impact time and enamel surface protection $[5,6]$.

Bleaching products comprise different composition of gels with different peroxide concentrations [7-9]. The decomposition of the peroxides results in free radicals. These free radicals break down large pigmented molecules in enamel into smaller, less pigmented molecules through either oxidation or reduction reactions $[3,10]$. The oxidation reaction should not exceed the saturation point, which the organic and inorganic elements of enamel and dentin are damaged. Otherwise, the crystals of enamel matrix proteins lead to adverse changes in the morphology of the tooth surface and weakened structure $[11,12]$.

Studies have shown that bleaching agents can cause structural alterations on the enamel surface and that the biomechanical properties

*Corresponding author: Cigdem Atalayin, Department of Restorative Dentistry, School of Dentistry, Ege University, 35100 Izmir -Turkey, Tel: +90 23231128 87; Fax: +90 23238803 25; E-mail: dtcatalayin@gmail.com

Received February 19, 2014; Accepted March 03, 2014; Published March 05, 2014

Citation: Kemaloglu H, Atalayin C, Tezel H (2014) Scanning Electron Microscopy Investigation of Enamel Surface Treated with Different Bleaching Agents. Dentistry 4: 222. doi:10.4172/2161-1122.1000222

Copyright: (c) 2014 Kemaloglu H, et al. This is an open-access article distributed under the terms of the Creative Commons Attribution License, which permits unrestricted use, distribution, and reproduction in any medium, provided the original author and source are credited. 
of the enamel can change [13-20]. Although 10\% CP has been shown to be safe and not to alter the enamel [20-22], there is still little information and a debate about the effects of bleaching products that present different peroxide concentrations, formulations and application protocols [23].

The aim of this in vitro study was to evaluate the effects of different bleaching agents with different concentration and activation methods on human enamel surface with scanning electron microscopy (SEM) to compare the changes caused by different bleaching agents visually. The hypothesis tested was that different bleaching treatments altered the enamel surface.

\section{Method and Materials}

Human impacted third molar teeth were rinsed in tap water and were cleaned off plaque and debris with a dental hand piece and a brush. The buccal, lingual and occlusal surfaces werechecked under a stereomicroscope, and teeth with enamel defects or cracks were rejected. The selected teeth $(n=5)$ were stored in $0.9 \%$ saline solution for one week and then rinsed indistilled water. Each tooth was sectioned buccolingually or bucco-palatinally into two halves with a diamond disc. These halves were then sectioned longitudinally into three parts, so that six specimens were obtained from each tooth. These specimens were randomly assigned to one of the six groups, ensuring that each part of every specimen would be in a different group, which was one of the six groups. Then, teeth were covered with wax except for the enamel surface.

The specimens in the first group were used as a control group, no agent was used and they were kept in artificial saliva [24-26] during the test period.

The second group of the specimens, to which home bleaching was applied, were placed on the anterior side of the phantom jaw in such a way that the enamel surfaces would face the buccal side. Stone casts were obtained from the impression made from a silicone impression material with type IV dental stone (Die-Keen; Heraeus KulzerInc, South Bent, Ind.). The enamel parts on the buccal surfaces of the casts were blocked out by a resin creating reservoirs. A vacuum tray was formed out of the soft tray sheet which had a thickness of $0.5 \mathrm{~mm} .10 \%$ CP (Opalescence PF 10\% CP, Ultradent Products Inc, South Jordan, USA) was added into this bleaching tray and was kept there for 8 hours a day throughout 14 days.

Following every session, the teeth were rinsed; dried and topical fluoride agent (Flor-Opa 11.1\% NaF, Ultradent Products Inc, South Jordan, USA) was applied for ten minutes. The specimens were kept in artificial saliva during the test period to take advantage of there mineralization action of saliva. The artificial saliva used in this study was freshened everyday to be able to obtain constant ion concentration.

In the third group, the bleaching gel consisting of $25 \% \mathrm{HP}$ (ZOOM 25\% hydrogenperoxide whitening gel, Discus Dental, LLC, Culver City, USA) was applied to the enamel surfaces $(\sim 1-1,5 \mathrm{~mm})$. The gel was activated with mercury metal halide light (ZOOM! Advanced Power, Discus Dental, USA) for fifteen minutes according to the manufacturer'sinstruction. The activation was repeated three times with the agitation of the gel. After the forty-five minutes of total activation time, whitening gel was removed, the teeth were rinsed, dried and the same topical fluoride agent was applied for ten minutes.

In the fourth group, the bleaching agent consisting of $38 \% \mathrm{HP}$ (Opalescence Boost 38\%HP, Ultradent Products Inc, South Jordan, USA) was applied to enamel surfaces of the specimens at about 1-1.5 $\mathrm{mm}$ thickness. The bleaching agent was activated with quartz tungsten- halogen (QTH) light on bleaching mode (Optilux 501, Kerr, USA) for 30 seconds.

The gel was replaced three times. The treatment time (total gel exposure) reduced to forty-five minutes with light activation. After removing the whitening gel, the teeth were rinsed, dried and the same topical fluoride agent was applied for ten minutes. The specimens were kept in artificial saliva until the following day. This procedure was repeated every other day for 3 days of application.

In the fifth group, a layer ( 1-1.5 mm) of $38 \% \mathrm{HP}$ (Opalescence Boost $38 \%$ HP, Ultradent Products Inc, South Jordan, USA) was applied to the enamel surfaces of the specimens. To have the optimum effectiveness, the bleaching gel was activated with diodelaser (LaserSmile, Biolase, USA) using the whitening program (10 Watt-continuous mode for 15 seconds). After each activation, the gel was agitated and the activation was repeated withone-minute intervals. This was repeated for four times. The application was repeated three times for every session. At the end of the application the teeth were rinsed, dried and the topical fluoride agent was applied for ten minutes. The specimens were kept in artificial saliva until the following day. This procedure was repeated 3 times every other day.

The specimens in the sixth group were treated with $37 \%$ orthophosphoric acid (ScotchBond Phosphoric Etchant Kit, 3M ESPE, USA) for 30 seconds, while the remaining 4 groups were treated with bleaching agents (from A3 shade to A1 shade); $10 \% \mathrm{CP}, 25 \% \mathrm{HP}$ activated with mercury metal halide light, 38\% HP activated with quartz-tungsten halogen light and 38\% HP activated with diode laser respectively according to manufacturers'instructions.

After the application of the bleaching agents for the prescribed time, the specimens were anticipated in artificial saliva for 14 days to mimic the in vivo remineralization condition.

Then the specimens were rinsed ultrasonically with water for ten minutes and prepared for SEM (FEI, QUANTA FEG 250) analysis. After dehydration, enamel surfaces were sputter coated with gold ( 30-35 $\mathrm{nm})$ and photomicrographs of representative areas were taken at $5000 \mathrm{x}$ and 10000x magnifications. The classification for the enamel changes were as follows; no alterations, mild or slight alterations, significant alterations and loss of superficial structures.

\section{Results}

Figure 1 shows a representative photomicrograph of enamel

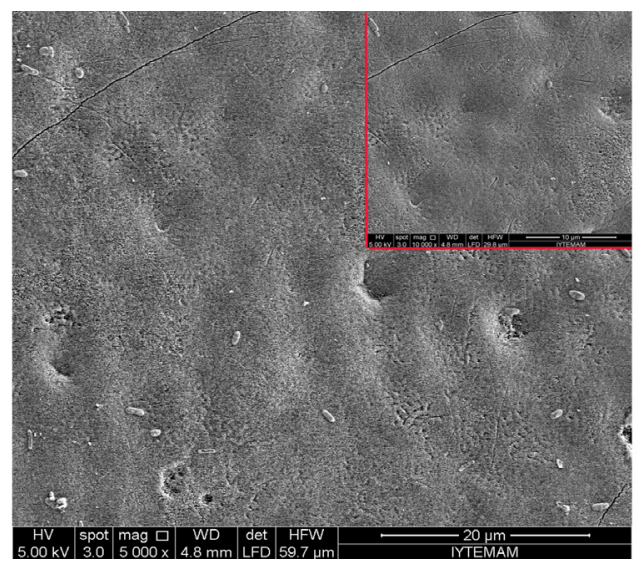

Figure 1: SEM micrograph of the sound enamel surface indicating 'no alterations'. 
surface stored in artificial saliva. Remarkable morphologic alterations were not detected on unbleached enamel surfaces. The surface was not completely smooth; however the aprismatic surface layer was uniform.

Circumferentially horizontal lines on the surface of normal, sound teeth known as perikymata was evident on all over the surface. In addition, pores could be easily seen and there weresome areas that comprised cracks.

Bleached groups showed alterations on surface smoothness and presented different levels of surface changes. Minor changes of the enamel surface occurred in samples treatedwith $10 \%$ CP for 8 hours daily for 14 days (Figure 2). This aspect suggested an insignificant increase in the enamel porosity, as compared to the control samples. The noted interprismatic limits were legend of the mild surface change.

The SEM pictures of enamel treated with 25\% HP activated with mercury metal halide light were similar to those of the control group. However, after a detailed analysis the dissolution of both the interprismatic and intraprismatic substance could be detected on the surface of enamel resulting slight alterations. Besides the surface was smooth and perikymata was indistinguishable (Figure 3).

Intraprismatic structure dissolution occurred on the surface treated with 38\% HP with light activation (Figure 4). The surface alterations were much more significant than the other bleaching groups with

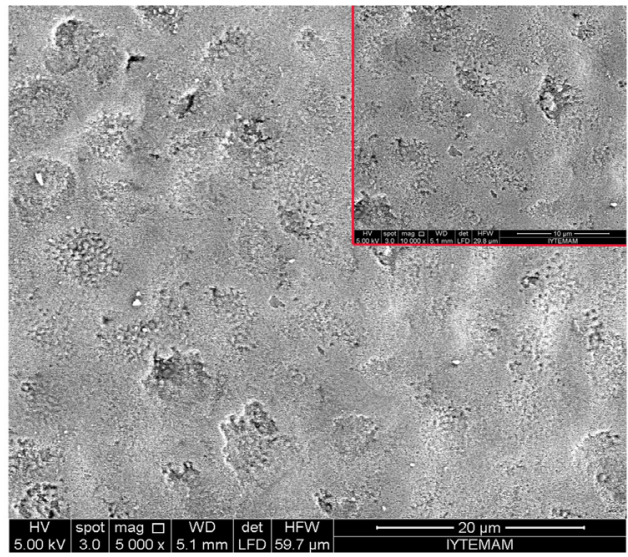

Figure 2: SEM micrograph of enamel surface treated with 10\% CP indicating 'mild' surface alterations.

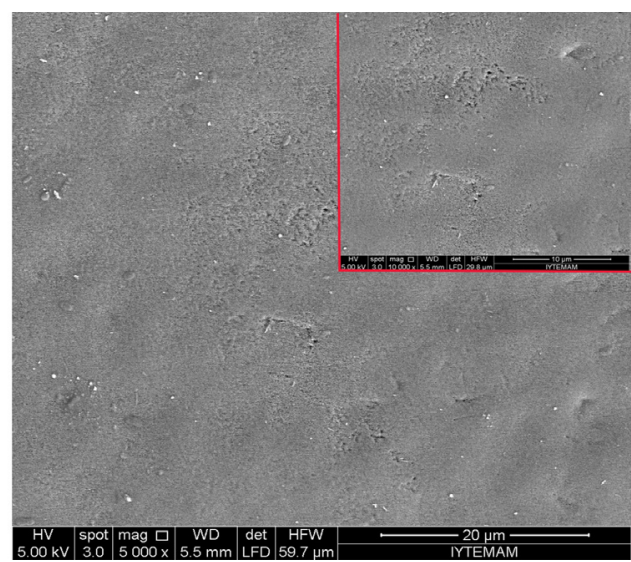

Figure 3: SEM micrograph of enamel surface treated with $25 \%$ HP activated with mercurymetal halide light indicating 'slight' alterations.

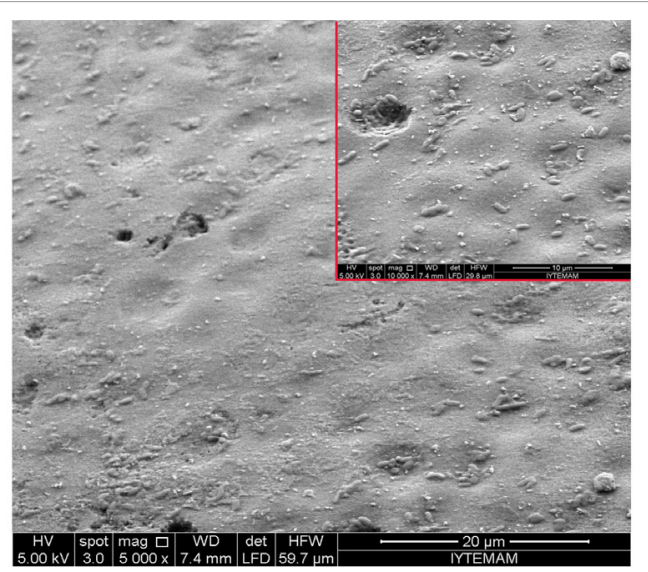

Figure 4: SEM micrograph of enamel surface treated with $38 \%$ HP with halogen light activation indicating 'significant' alterations.

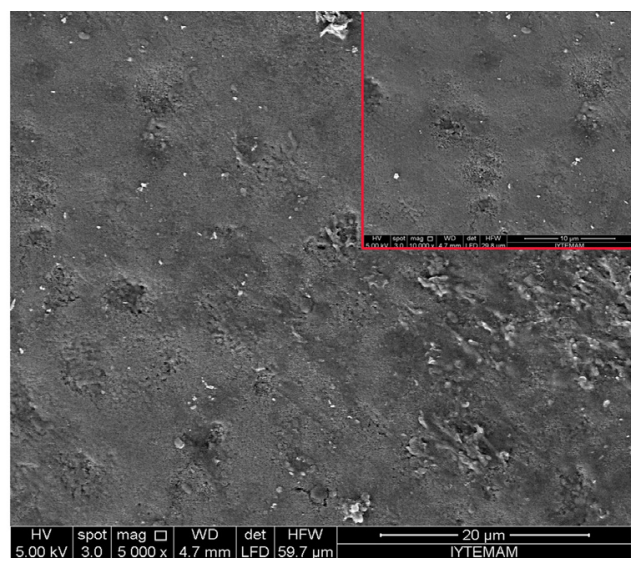

Figure 5: SEM micrograph of enamel surface treated with $38 \%$ HP with diode laser activation indicating 'slight' alterations.

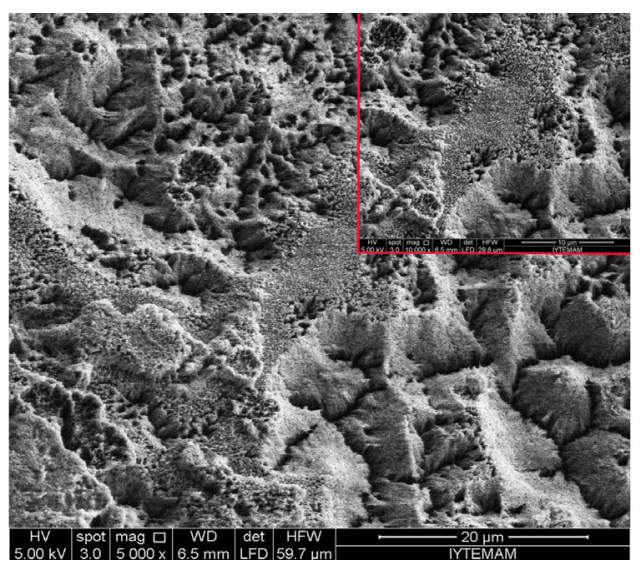

Figure 6: SEM micrograph of enamel surface treated with $37 \%$ orthophosphoric acid indicating 'loss of superficial structure'.

widespread and intense surface deposits. Porosity and concavity of the enamel structure increased due to intraprismatic dissolution.

Mild alterations on surface smoothness and slightly increased porosity occurred in the teeth bleached with 38\% HP with laser activation (Figure 5). Interprismatic dissolution could be clearly 
observed. These changes were similar to the image of $10 \% \mathrm{CP}$ group (Figure 3), but additionally spattered deposits on the surface were also noted. In the sixth group, the acid-etched samples had a rough and uneven surface, which indicated alterations of the prismatic structure of the enamel due to selective dissolution of the apatite crystals (Figure 6). Formation of an irregular meshwork and dissolution in central (intraprismatic) or peripheral (interprismatic) part of the prism took place as a result of demineralization. The loss of superficial structure was evident.

\section{Discussion}

Surveying the literature, it is noticeable that the studies on bleaching are mostly about the aesthetic outcomes and clinical performance of different treatment techniques with different activation methods [2729]. In addition there are many studies that evaluated the structural changes of dental hard tissues with microhardness tests, profilometric analyzes and spectrophotometric mineral loss measurements [18$20,23]$. Besides, in the present study it was aimed to compare the changes caused by different bleaching agents with different concentration and activation methods on human enamel surface with SEM and visualize the structural changes with photomicrographs. Our hypothesis that different bleaching treatments would alter the enamel surface was proven according to the visual evaluations, which revealed surface alterations on enamel after all bleaching procedures. The results were classified according to a certain scale as no alterations, mild or slight alterations, significant alterations and loss of superficial structures.

Effects of different bleaching agents on enamel structure have been discussed innumerous studies and most of these studies have reported that in-office bleaching agents caused more pronounced effects than home-bleaching agents due to its higher HP concentration [13-23]. However, there have been controversial results on the effects of CP.

Some studies have demonstrated no significant effects of $10 \% \mathrm{CP}$ that has been approved tobe the safest agent by ADA [20-22]. On the other hand, contrary results have shown the morphological alterations on enamel surface bleached with $10 \%$ CP $[13,30]$.

In the present study, the specimens of the control group stored in artificial saliva for 14 days showed no changes in morphology. The intact uniform surface layer could be observed. On the contrary, all the agents tested caused defects on the enamel surface with different characteristics. Ten percent CP caused mildly changed areas on enamel surface after the application time of 8 hours/day for 14 days, which added up to 112 hours of total contact time with the bleaching agent. The expectation would be that $10 \% \mathrm{CP}$ would not cause any alterations on enamel surface and the surface would look like the control group. However, the morphological analyzes showed slight alterations on enamel porosity and noted interprismatic limits.

Light activation have been used to increase the reaction rate and accelerate the decomposition reaction of HP. Currently different types of light sources are being used fortooth bleaching, including quartztungsten-halogen (QTH) lamps, plasma arc, light emitting diodes and lasers $[31,32]$. Mercury metal halide lamps work in a similar way to plasma arclamps with a little difference that the source of light emission is metal ions instead of ionized xenon gas. Plasma arc lamps emit a wide range of wavelength while lasers emit a well-defined monochromatic light at a single wavelength [33].

The alterations of the surface characteristics of the 25\% HP group which were activated by mercury alkali metal light activation was an interesting finding of the present study. The surface morphology was so smooth that it was nearly close to the control group with little differences. It could also be seen that perikymata has become indistinguishable, creating flatter enamel surfaces. Following light activation, the surface morphology was substantially changed and became smoother. In addition, the dissolution of both the interprismatic and intraprismatic substance could be detected. In a study [34], the temperature rise of enamel surface after bleaching with mercury metal halide light and diode laser were compared. The temperature rise of mercury metal halide light found to be significantly higher than diode laser for the first application of the treatment procedure. The results of mercury metal halide light were also higher for the latter applications however; there was significantly no difference between the groups. The authors of the present study believe that the heat induced by mercury metal halide, which did not exceed $8^{\circ} \mathrm{C}$ in Abu-El Magd's study [34] might have changed the structure of apatite crystals on surface and caused alterations on the enamel surface. In another study by Nelson et al. [35], it was shown that heat delivered by infrared laser irradiation resulted in a melted surface with a new phase of lower carbonate content. Within the light of above studies, the smoother surface formed after the application of mercury metalhalide activation could be attributed to the heat induced by light activation. It is a possibility that mercury metal halide activation might have melted the surface layer of enamel causing as moother surface.

Morphological analyzes of enamel surface treated with 38\% HP activated with halogen light have shown severe surface alterations. However mild surface alterations were noted in the fifth group which the same concentration of HP was activated with diode laser. Dostalova et al. [5] evaluated the effects of various diode laser techniques for bleaching teeth and concluded that diode lasers helped to decrease the time of bleaching without surface modifications. Both groups represented increased porosity in the present study; however, the deposits of the light activated group were much higher. Increased porosity and deposit precipitation characterize the enamel erosion [3638]. Thus, the alterations on the enamel surface of the light-activated group were most likely erosions, as also demonstrated in an invitro study by Tezel et al. $[20,23]$. The difference among these studies can be attributed to the effect of contact time with the agent and the activation time of the gel. The total contact time was 45 minutes for the light activated group and 36 minutes for the laser activated group.

The etching with phosphoric acid, which was first mentioned by Buonocore in 1955, is used in contemporary practice in dentistry in order to increase the bond strength of adhesive materials to enamel. Since then, different concentrations of phosphoric acid have been widely used to etch enamel surfaces. Its effect on enamel varies; as several different arrangements ofdissolved crystals form [39]. In the present study, one sixth of each tooth was treated with $37 \%$ phosphoric acid in order to compare the surface characteristics of bleached and the etched enamel surfaces. When the specimens were analyzed, a significant amount of structure loss and an aggressive change in the structure of the enamel were observed. It was known that after phosphoric acid etching approximately $10 \mu \mathrm{m}$ of the enamel surface has been removed and porous surface layer has been formed [40,41]. In addition, the surface was irregular and the dissolution pattern was not uniform throughout the surfaces. Although extensive demineralization could be seen clearly, there were some areas showing the aprismatic layer of the third molar teeth used in the study.

\section{Conclusion}

In the limitation of this study it can be concluded that, all bleaching agents caused changes on the surface morphology of extracted human 
Citation: Kemaloglu H, Atalayin C, Tezel H (2014) Scanning Electron Microscopy Investigation of Enamel Surface Treated with Different Bleaching Agents. Dentistry 4: 222. doi:10.4172/2161-1122.1000222

teeth with more or less differences. Among the bleaching systems investigated, $10 \% \mathrm{CP}$ should be the first choice for a bleaching treatment if the patient has enough time. If not, it can be concluded that office bleaching with laser activation is the safest method to use when the possible adverse effects on enamel surface are considered. For all the changes observed in all groups, it is important to investigate whether these changes are reversible or not. In addition bacterial accumulation, protective effect of remineralization agents and the nano identification of the structure of the apatite crystals should be investigated in the future studies in order to understand the alteration and dissolution phenomena better after bleaching.

\section{Acknowledgement}

We sincerely thank Prof. Dr. Gulperi Oktem for her kind help and support.

\section{References}

1. Javaheri DS, Kugel G, Janis JN (2001) Current status of at home bleaching Practical Procedures and Aesthetic Dentistry 13: 10-13.

2. Kelleher MGD, Roe FJC (1999) The safety-in-use of $10 \%$ carbamide peroxide (Opalescence) for bleaching teeth under the supervision of a dentist. Br Dent J 187: 190-194.

3. Haywood VB (1992) History, safety and effectiveness of current bleaching techniques and applications of the nightguard vital bleaching technique. Quintessence Int 23: 471-488.

4. Li Y (1996) Biological properties of peroxide-containing tooth whiteners. Food Chem Toxicol 34: 887-904.

5. Dostalova T, Jelinkova H, Housova D, Sulc J, Nemec M, et al. (2004) Diode Laser-Activated Bleaching. Braz Dent J 15: 1-8.

6. Goharkhay K, Schoop U, Wernisch J, Hartl S, De Moor R, et al. (2009) Frequency doubled neodymium:yttrium-aluminum-garnet and diode laseractivated power bleching-pH, enviromental scanning electron microscopy, and colorimetric in vitro evaluations. Laser Med Sci 24: 339-346.

7. Clark DM, Hintz J (1998) Case report: in-office tooth whitening procedure with $35 \%$ carbamide peroxide evaluated by the Minolta CR-321 Chroma Meter. J Esthet Dent 10: 37-42.

8. Haywood VB, Robinson RG (1997) Vital tooth bleaching with nightguard vital bleaching. Curr Opin Cosmet Dent 4: 45-52.

9. Lyons K, Ng B (1998) Nightguard vital bleaching: a review and clinical study. $\mathrm{N}$ Z Dent J 94: 100-105.

10. Chen JH, Xu JW, Shing CX (1993) Decomposition rate of hydrogen peroxide bleaching agents under various chemical and physical conditions. J Prosthet Dent 69: 46-48.

11. Haywood VB, Heymann HO (1989) Nightguard vital bleaching. Quintessence Int 20: 173-176.

12. Goldstein GR, Garber DA (1995) Complete Dental Bleaching. Quintessence Int, Chiacago.

13. Seghi RR, Denry I (1992) Effects of external bleaching on indentation and abrasion characteristics of human enamel in vitro. J Dent Res 71: 1340-1344.

14. Flaitz CM, Hicks MJ (1996) Effects of carbamide peroxide whitening agents on enamel surface and caries like lesion formation: A SEM and polarized ligh microscopic in vitro study. J Dent Child 63: 249-256.

15. Bitter NC (1992) A scanning electron microscopy study of of the effect of bleaching agents on enamel: A preliminary report. J Prosthet Dent 67: 852-855.

16. Covington JS, Friend GW, Lamoreaux WJ, Perry T (1990) Carbamide Peroxide tooth bleaching: Effect on enamel composition and topograph. J Dent Res 69: 175 .

17. Hegedüs C, Bistey T, Flora-Nagy E, Keszthelyi G, Jenei A (1999) An atomic force microscopy study on the effect of bleaching agents on enamel surface. $J$ Dent 27: 509-515.

18. Rotstein I, Danker E, Goldman A, Helling I, Stahbolz A, et al. (1996) Histochemical analysis of dental hard tissues following bleaching. J Endod 22: 23-25
19. Potocnick I, Kosec L, Gaspersic D (2000) Effect of $10 \%$ carbamide peroxide bleaching gel on enamel microhardness, microstructure and mineral content. J Endod 26: 203-206.

20. Tezel H, Ertaş SÖ, Özata F, Dalgar H, Korkut Z (2007) Effect of bleaching agen on calcium loss from the enamel surface. Quintessence Int 38: 339-347.

21. McCracken MS, Haywood VB (1996) Demineralization effects of $10 \%$ carbamide peroxide. J Dent 24: 393-398.

22. Haywood VB, Leech T, Heymann HO, Crumpler D, Bruggers K (1990) Nightguard vital bleaching: effects on enamel surface texture and diffusion. Quintessence Int 21: 801-804.

23. Tezel H, Atalayin C, Erturk O, Karasulu E (2011) Susceptibility of Ename Treated with Bleaching Agents to Mineral Loss after Cariogenic Challenge. Int J Dent 2011: 953835.

24. Eisenburger M, Addy M, Hughes JA, Shellis RP (2001) Effect of time on the remineralization of enamel by synthetic saliva after citric acid erosion. Caries Res 35: 211-215.

25. Lippert F, Parker DM, Jandt KD (2004) Toothbrush abrasion of surface softened enamel studied with tapping mode AFM and AFM nanoindentation. Caries Res 38: $464-472$.

26. Barbour ME, Rees JS (2004) The laboratory assessment of enamel erosion: A review. J Dent 32: 591-602.

27. Bernardon JK, Sartori N, Ballarin A, Perdigão J, Lopes G, et al. (2010) Clinica Performance of Vital Bleaching Techniques. Oper Dent 35: 3-10.

28. Marson FC, Sensi LG, Vieira LC, Araújo E (2008) Clinical evaluation of in-office dental bleaching treatments with and without the use of light-activation sources. Oper Dent 33: 15-22.

29. Deliperi S, Bardwell DN, Papathanasiou A (2004) Clinical evaluation of a combined in office and take-home bleaching system. J Am Dent Assoc 135 628-634.

30. Oltu U, Gurgan S (2000) Effects of three concentrations of carbamide peroxide on the structure of enamel. J Oral Rehabil 27: 332-340.

31. Lizarelli RFZ, Moriyama LY, Bagnato VS (2002) A non-vital tooth bleaching technique with laser and LED. J Oral Laser Appl 2: 45-47.

32. Wetter NU, Barosso MC, Pelino JEP (2004) Dental bleaching efficacy with diode laser and LED irradiation: an in vitro study. Lasers Surg Med 35: 254-258.

33. Buchallaa W, Attin T (2007) External bleaching therapy with activation by heat light or laser-A systematic review. Dent Mater 23: 586-596.

34. Abu-EIMagd DM, El-Sayad II, Abd El-Gawad LM (2009) Tooth whitening and temperature rise with two bleaching activation methods. Lasers in Dentistry.

35. Nelson DG, Wefel JS, Jongebloed WL, Featherstone JD (1987) Morphology, histology and crystallography of human dental enamel treated with pulsed low energy infrared laser radiation. Caries Res 21: 411-426.

36. Titley K, Torneck CD, Smith D (1988) The effect of concentrated hydrogen peroxide solutions on the surface morphology of human tooth enamel. J Endod 14: 69-74.

37. Bitter NC, Sanders JL (1993) The effect of four bleaching agents on the ename surface: a scanning electron microscopic study. Quintessence Int 24: 817-824.

38. Miranda CB, Pagani C, Benetti AR, Da Silva MF (2005) Evaluation of the bleached human enamel by Scanning Electron Microscopy. J Appl Oral Sci 13: 204-211.

39. Buonocore MG (1955) A simple method of increasing the adhesion of acrylic filling materials to enamel surfaces. J Dent Res 34: 849-853.

40. Retief DH (1973) Effect of conditioning the enamel surface with phosphoric acid. J Dent Res 52: 333-341.

41. Silverstone LM, Saxton CA, Dogon IL, Fejerskov O (1975) Variation in the pattern of acid etching of human dental enamel examined by scanning electron microscopy. Caries Res 9: 373-387. 